\title{
Prevalence of Chronic Constipation and Its Associated Factors in Pars Cohort Study: A Study of 9000 Adults in Southern Iran
}

\author{
Parinaz Moezi ${ }^{1}$, Alireza Salehi ${ }^{3}{ }^{*}$, Hossein Molavi ${ }^{1}$, Hossein Poustchi ${ }^{2}$, \\ Abdullah Gandomkar ${ }^{3}$, Mohammad Hadi Imanieh ${ }^{4}$, Reza Malekzadeh ${ }^{5}$
}

1. Candidate for MPH Degree, MPH Department, Shiraz Medical School, Shiraz University of Medical Sciences, Shiraz, Iran

2. Associate Professor of Epidemiology, Liver, Pancreatic, and Biliary Diseases Research Center, Digestive Disease Research Institute, Tehran University of Medical Sciences, Tehran, Iran

3. Associate Professor of Epidemiology, Non-Communicable Disease Research Center, Shiraz University of Medical Sciences, Shiraz, Iran

4. Professor, Gastroenterohepatology Research Center, Shiraz University of Medical Sciences, Shiraz, Iran

5. Professor, Digestive Disease Research Center, Tehran University of Medical Sciences, Tehran, Iran

\section{* Corresponding Author:}

Alireza Salehi, MD, MPH, PhD of Epidemiology

Non-Communicable Disease Research Center, Shiraz University of Medical Sciences, Zand Avenue, Shiraz, Iran Tel: + 987132337589

Fax: + 987132338476

Email: salehialireza45@yahoo.com

Received: 01 Dec. 2017

Accepted: 11 Mar. 2018

\section{ABSTRACT}

\section{BACKGROUND}

Chronic constipation is one of the most common gastrointestinal disorders. It has negative effects on the patients' quality of life, and their productivity, and results in a high economic burden on the healthcare services. The aim of the present study was to estimate the prevalence of chronic constipation and its associated factors in pars cohort study (PCS).

\section{METHODS}

A cross-sectional study was conducted on the baseline data of the PCS. Data gathering was done by structured questionnaire and physical examination. A total of 9264 subjects aged between 40 and 75 years were enrolled in the PCS. Diagnosis of chronic constipation was done using Rome IV criteria. Multivariable binary logistic regression was applied for data analysis.

\section{RESULTS}

A total of $752(8.1 \%)$ participants were diagnosed as having chronic constipation $(9.3 \%$ of female and $6.7 \%$ of male participants). Older age (OR: $1.55,95 \%$ CI: $1.31-1.83$ ), physical activity (OR: 0.56, 95\% CI: 0.46-0.68), opium consumption (OR: 2.06, 95\% CI: 1.63-2.60), anxiety (OR: $1.38,95 \%$ CI: $1.15-1.65)$, depression (OR: $1.22,95 \%$ CI: 1.01-1.48), back pain or arthralgia (OR: $1.38,95 \%$ CI: $1.14-1.67$ ), insomnia (OR: $1.62,95 \%$ CI: 1.36-1.93) and gastroesophageal reflux disease (OR: $1.51,95 \%$ CI: $1.28-1.78$ ) were associated with the prevalence of constipation in the multivariable analysis.

\section{CONCLUSION}

Chronic constipation was a common problem in the PCS population. Decreasing modifiable risk factors associated with constipation such as opium consumption and physical inactivity can reduce its prevalence and decrease burden of the disease.

\section{KEYWORDS:}

Epidemiology, Chronic constipation, Rome IV criteria, Opium, Iran, Risk factors

Please cite this paper as:

Moezi P, Salehi A, Molavi H, Poustchi H, Gandomkar A, Imanieh MH, Malekzadeh R. Prevalence of Chronic Constipation and Its Associated Factors in Pars Cohort Study: A Study of 9000 Adults in Southern Iran. Middle East J Dig Dis 2018;10:75-83. doi: 10.15171/mejdd.2018.94.

\section{INTRODUCTION}

Constipation has been defined as infrequent, difficult (hard consistency or with straining), or incomplete evacuation. Chronic constipation (CC) is one of the most common gastrointestinal disorders. In some populations it is the most common digestive complaint, which leads to a high number of medical visits 
and imposes high costs to the healthcare service. ${ }^{1}$ Previous studies have reported a wide range of prevalence for $\mathrm{CC}$ (2-27\% with an average of $15 \%$ in most studies). ${ }^{2,3}$ This wide range is due to different study populations and also different inclusion criteria, for example studies that reported the prevalence based upon self-reporting, showed higher prevalence compared with those that used Rome criteria ${ }^{4}$ or studies conducted in southeast Asia reported lower prevalence compared with American and European studies. ${ }^{5-7}$

Due to these variations in prevalence, most recent studies have used Rome criteria, which are standardized and more expansive consensus criteria for diagnosing functional gastrointestinal disorders. The last version of this criteria is Rome IV that was released in May $2016 .{ }^{8}$

$\mathrm{CC}$ has different etiologies. It may be due to secondary causes including metabolic disorders, electrolyte imbalance, neurological disorders, colorectal structural disorder, and use of specific medications. ${ }^{9}$ Although only a few patients with chronic constipation have these secondary causes, when dealing with a patient with constipation in practice these causes also should be in consideration. Functional constipation (FC) is the most common form of $\mathrm{CC}$ and its diagnosis is made after exclusion of alarm symptoms (significant weight loss, hematochezia or positive occult blood test, anemia, acute constipation, positive family history of colon cancer, etc.) and secondary causes. Patients with FC are categorized into three subgroups based on the pathophysiology; patients with normal colonic transit (NCT), those with slow colonic transit (SCT), and those with functional defecatory disorders. Diagnostic and treatment approaches in these three subgroups are different from each other. ${ }^{10}$

Some of the risk factors for functional constipation based on previous studies are female sex, older age, low socioeconomic status, physical inactivity, and insufficient fluid and fiber consumption. ${ }^{7,11,12}$

$\mathrm{CC}$ is a major health problem. It has negative effects on the patients' quality of life, and their productivity, and results in a high economic burden on the healthcare services. ${ }^{13,14}$ There are a few studies on the prevalence of chronic constipation in Iran and especially in southern Iran. So we conducted present study to investigate the prevalence of $\mathrm{CC}$ and its associated factors in one of the largest cohort studies conducted in the south of Iran in order to provide a baseline data for further future trials.

\section{MATERIALS AND METHODS}

\section{Study Subjects and setting}

Baseline data of pars cohort study (PCS) were analyzed in cross-sectional design. PCS was launched in 2012 in Valashahr district, a rural area located in southern Iran. Valashahr district has more than 40,000 inhabitants mainly of Fars or Turk ethnicities. A total of 9264 participants aged between 40 to 75 years were enrolled in the study. Data were collected by using a structured questionnaire in addition to physical examination. Further details of the study protocol and preliminary results have been published previously. ${ }^{15}$

\section{Ethical consideration}

The study protocol was approved by research committees of both Tehran and Shiraz Universities of Medical Sciences and it is in accordance with the 1964 Helsinki declaration. Informed consent was obtained from all the participants.

\section{Study outcome}

$\mathrm{CC}$ was measured and then defined according to Rome IV questionnaire and criteria. ${ }^{16}$ The participants were categorized as having $\mathrm{CC}$ or not. The pattern of independent variables in patients was compared with those who did not have CC.

\section{Variables measurement}

In spite of a large number of variables measured in PCS (e.g. more than 180 variables) mostly by self-report and partly by physical examinations and biological samples, a shorter list of variables was selected. Independent variables were selected according to a conceptual framework, in which all potential associated factors of the $\mathrm{CC}$ were identified and analyzed according to biological considerations as well as evidence on the determinants of the prevalence of the CC. Accordingly, age, sex, body mass index, systolic and diastolic blood pressure, educational level, socio-economic status, marital status, ethnicity, physical activity, smoking, opium and alcohol consumption, and self-reported medical diseases (heart disease including heart failure, angina and myocardial infarction), stroke, hypertension, diabetes mellitus, liver 
disease, chronic kidney disease, chronic obstructive pulmonary disease, anxiety, depression, back pain or arthralgia, insomnia, history of previous surgery, history of previous cancer, and gastroesophageal reflux disease (GERD) were considered as associated factors of the prevalence of the $\mathrm{CC}$.

\section{Data preparation}

Body mass index was categorized based on WHO definition into subgroups (e.g. underweight as less than 18.5, normal as 18.5 to 24.9 , overweight as 25 to 29.9 , and obese as 30 and above.) Ethnicity was categorized into two main groups including Fars and non-Fars (Turk and other minorities). Educational level was classified as illiterate, less than 5 years, ${ }^{6-12}$ years, and university degree. Applying multiple correspondence analysis socioeconomic scores were estimated, ${ }^{17}$ and then categorized into five quintiles. The value of Metabolic Equivalent of Task (MET) score as a measure of physical activity was calculated applying standard method recommended for analysis of international physical activity questionnaire (IPAQ). MET scores were then categorized into three thirties, hereafter, low, medium, and high physical activity.

In case of cigarette and non-cigarette tobacco and also opium consumption, the participants with at least once per week for the past six months were considered as users. While in case of alcohol consumption, the participants who used once per month for the past 6 months were considered as alcohol users.

\section{Statistical analysis}

Data quality was assessed. Univariate and multivariate outliers were identified and handled in an appropriate recommended manner. ${ }^{18}$ Internal and external inconsistencies were also identified and handled. Rate and pattern of missing data were analyzed.

Data were described by means and standard deviations and/or frequencies and relative frequencies (for qualitative variables). Independent samples t test or MannWhitney U test were used for comparison of quantitative variables and Chi square and/or Fisher's exact test were used for comparison of qualitative variables. Variables with a univariate $p$ value of less than 0.1 were retained in the multivariate logistic regression model. Backward likelihood ratio elimination approach was applied for binary multivariate logistic regression. $P$ values less than 0.05 were considered as statistically significant. Statistical analyses were done using SPSS software version 23 (SPSS Inc., Chicago, IL, USA).

\section{RESULTS}

Overall 9264 participants were enrolled in PCS. Of them 4276 (46.2\%) were male and 4988 (53.8\%) were female participants, with a mean age of $52.6 \pm 9.7$ years. A total of $752(8.1 \%, 95 \%$ CI: 7.6-8.7) participants were diagnosed as having $\mathrm{CC}$. Patients with $\mathrm{CC}$ were older than participants without CC $(55.7 \pm 10.8$ vs. $52.4 \pm 9.5$ years; $p<0.001)$. The prevalence of CC was $9.3 \%(95 \%$ CI: 8.5-10.2) for women, and 6.7\% (95\% CI: 5.9-7.5) for men (table 1).

The prevalence of the $\mathrm{CC}$ among cigarrete ever and never users were $7.8 \%$ (95\% CI: 6.7-9.2) and 8.2\% (95\% CI: 7.5-8.8), respectively. The prevalence of $\mathrm{CC}$ for participants who had been reported to be illiterate was 9.0\% (95\% CI: 8.0-10.0) and for other participants was 7.2\% (95\% CI: 6.5-8.1). Divorced or widow participants had a prevalence of $12.9 \%$ (95\% CI: 10.5-15.7). The prevalence of CC among participants who aged 60 years and above was estimated at $11.9 \%$ (95 \% CI: 10.5-13.5) (table 1).

The participant with lower physical activity had a higher prevalence of CC compared with those who were physically more active $(10.1 \%, 95 \%$ CI: 9.8-12.1 vs. $5.6 \%$, 95\% CI: 4.8-6.5). Estimated prevalence of CC was $9.1 \%$ (95\% CI: 7.8-10.4) for participants in lower economic level and 6.5\% (95\% CI: 5.4-7.9) for those who were in higher level. There was no significant relation between body mass index and CC ( $p=0.08$, table 1$)$.

Sex-stratified comparison of smoking, and opium and alcohol consumption was done, which showed cigarette smoking and opium consumption were significantly associated with $\mathrm{CC}$ in men (unadjusted OR for opium consumption in men was 2.70 with a $95 \%$ CI: $2.09-3.5$ ) (table 2).

Univariate analysis showed that the prevalence of CC was significantly higher in patients with self-reported heart disease $(p<0.001)$, stroke $(p=0.001)$, diabetes mellitus $(P<0.001)$, anxiety $(p<0.001)$, depression $(p$ $<0.001)$, back pain or arthralgia $(p<0.001)$, insomnia $(\mathrm{p}<0.001)$, history of previous surgery $(p=0.001)$, and 
Table 1: Demographic, anthropometric, and lifestyle characteristics of patients with and/or without chronic constipation

\begin{tabular}{|c|c|c|c|c|}
\hline Variables & & $\mathrm{CC}(\mathrm{n}=752)$ & No CC $(n=8511)$ & $P$ value \\
\hline Age & & $55.7 \pm 10.8$ & $52.4 \pm 9.5$ & $<0.001$ \\
\hline \multirow[t]{2}{*}{ Sex } & Female & $466(62 \%)$ & $4521(53.1 \%)$ & \multirow{2}{*}{$<0.001$} \\
\hline & Male & $286(38 \%)$ & $3990(46.9 \%)$ & \\
\hline \multirow[t]{3}{*}{ BMI } & Underweight and normal & $322(42.9 \%)$ & $3778(44.6 \%)$ & \multirow{3}{*}{0.08} \\
\hline & Overweight & $269(35.9 \%)$ & $3173(37.5 \%)$ & \\
\hline & Obese & $159(21.2 \%)$ & $1511(17.9 \%)$ & \\
\hline \multirow[t]{2}{*}{ Ethnicity } & Fars & $468(62.2 \%)$ & $4748(55.8 \%)$ & \multirow[b]{2}{*}{0.001} \\
\hline & $\begin{array}{l}\text { Non Fars (Turk and } \\
\text { others) }\end{array}$ & $284(37.8 \%)$ & $3763(44.2 \%)$ & \\
\hline \multirow[t]{3}{*}{ Marital status } & Single & $19(2.5 \%)$ & $278(3.3 \%)$ & \multirow{3}{*}{$<0.001$} \\
\hline & Married & $636(84.6 \%)$ & $7575(89 \%)$ & \\
\hline & Divorced/widow & $97(12.9 \%)$ & $655(7.7 \%)$ & \\
\hline \multirow[t]{4}{*}{ Educational level } & Illiterate & $408(54.4 \%)$ & $4130(48.6 \%)$ & \multirow{4}{*}{0.002} \\
\hline & $\leq 5$ years & $219(29.9 \%)$ & $2511(29.5 \%)$ & \\
\hline & $6-12$ years & $106(14.1 \%)$ & $1601(18.8 \%)$ & \\
\hline & University & $17(2.3 \%)$ & $264(3.1 \%)$ & \\
\hline \multirow[t]{3}{*}{ Physical activity } & Low & $339(45.1 \%)$ & $2766(32.5 \%)$ & \multirow{3}{*}{$<0.001$} \\
\hline & Medium & $239(31.8 \%)$ & $2828(33.3 \%)$ & \\
\hline & High & $174(23.1 \%)$ & $2911(34.2 \%)$ & \\
\hline \multirow[t]{5}{*}{ Wealth score } & Quintile 1 & $197(26.2 \%)$ & $1978(23.2 \%)$ & \multirow{5}{*}{0.024} \\
\hline & Quintile 2 & $124(16.5 \%)$ & $1438(16.9 \%)$ & \\
\hline & Quintile 3 & $181(24.1 \%)$ & $1823(21.4 \%)$ & \\
\hline & Quintile 4 & $136(18.1 \%)$ & $1644(19.3 \%)$ & \\
\hline & Quintile 5 & $114(15.2 \%)$ & $16289(19.1 \%)$ & \\
\hline
\end{tabular}

$P$ was calculated by: Mann-Whitney $\mathrm{U}$ test, $\mathrm{X} 2$ test and Fisher exact test CC: Chronic constipation, BMI: body mass index

Table 2: Sex-stratified comparison of smoking, and opium and alcohol consumption

\begin{tabular}{|c|c|c|c|c|c|c|c|}
\hline \multirow[b]{2}{*}{ Variables } & & \multicolumn{3}{|c|}{ Men $(n=4286)$} & \multicolumn{3}{|c|}{ Women $(n=4988)$} \\
\hline & & $\mathrm{FC}(\mathrm{n}=286)$ & No FC $(n=3990)$ & $P$ value & FC $(n=466)$ & No FC $(n=4521)$ & $P$ value \\
\hline \multirow[t]{2}{*}{ Cigarette ever used } & Yes & $144(50.3 \%)$ & $1745(43.8 \%)$ & \multirow{2}{*}{0.032} & $8(1.7 \%)$ & $43(1 \%)$ & \multirow{2}{*}{0.12} \\
\hline & No & $142(49.7 \%)$ & $2238(56.2 \%)$ & & $458(98.3 \%)$ & $4471(99 \%)$ & \\
\hline \multirow{2}{*}{$\begin{array}{l}\text { Non-cigarette } \\
\text { tobacco ever used }\end{array}$} & Yes & $95(33.3 \%)$ & $1136(28.5 \%)$ & \multirow{2}{*}{0.083} & $235(50.4 \%)$ & $2071(45.9 \%)$ & \multirow{2}{*}{0.063} \\
\hline & No & $190(66.7 \%)$ & $2848(71.5 \%)$ & & $231(49.6 \%)$ & $2440(54.1 \%)$ & \\
\hline \multirow[t]{2}{*}{ Opium ever used } & Yes & $98(34.3 \%)$ & $645(16.2 \%)$ & \multirow{2}{*}{$<0.001$} & $2(0.4 \%)$ & $29(0.6 \%)$ & \multirow{2}{*}{0.56} \\
\hline & No & $188(65.7 \%)$ & $3345(83.8 \%)$ & & $464(99.6 \%)$ & $4492(99.4 \%)$ & \\
\hline \multirow[t]{2}{*}{ Alcohol consumption } & Yes & $17(5.9 \%)$ & $149(3.7 \%)$ & \multirow{2}{*}{0.062} & $2(0.4 \%)$ & $28(0.6 \%)$ & \multirow{2}{*}{0.61} \\
\hline & No & $269(94.1 \%)$ & $3841(96.3 \%)$ & & $464(99.6 \%)$ & $4493(99.4 \%)$ & \\
\hline
\end{tabular}

$P$ was calculated by: $\mathrm{X} 2$ test and fisher exact test

CC: Chronic constipation, FC: Functional constipation

GERD $(p<0.001)$. No association was found between $\mathrm{CC}$ and liver disease, chronic kidney disease, chronic obstructive pulmonary disease, and history of previous cancer (table 3).
Older age (OR:1.55, 95\% CI:1.31-1.83), physical activity (OR: $0.56,95 \% \mathrm{CI}: 0.46-0.68)$, opium consumption (OR: 2.06, 95\% CI: 1.63-2.60), anxiety (OR: 1.38, 95\% CI: 1.15-1.65), depression (OR: 1.22, 95\% CI: 
Table 3: Comparison of the history of medical diseases between the patients with and/or without chronic constipation

\begin{tabular}{|c|c|c|c|c|}
\hline Variables & & $C C(n=752)$ & No $C C(n=8511)$ & $P$ value \\
\hline \multirow[t]{2}{*}{ Heart disease } & Yes & $120(16 \%)$ & $841(9.9 \%)$ & \multirow{2}{*}{$<0.001$} \\
\hline & No & $632(84 \%)$ & $7670(90.1 \%)$ & \\
\hline \multirow[t]{2}{*}{ Stroke } & Yes & $25(3.3 \%)$ & $141(1.7 \%)$ & \multirow{2}{*}{0.001} \\
\hline & No & $627(96.7 \%)$ & $8370(98.3 \%)$ & \\
\hline \multirow[t]{2}{*}{ HTN } & Yes & $170(22.6 \%)$ & $1343(15.8 \%)$ & \multirow{2}{*}{$<0.001$} \\
\hline & No & $582(77.4 \%)$ & $7168(84.2 \%)$ & \\
\hline \multirow[t]{2}{*}{ Diabetes mellitus } & Yes & $102(13.6 \%)$ & $772(9.1 \%)$ & \multirow{2}{*}{$<0.001$} \\
\hline & No & $650(86.4 \%)$ & $7739(90.9 \%)$ & \\
\hline \multirow[t]{2}{*}{ Anxiety } & Yes & $320(42.6 \%)$ & $2424(28.5 \%)$ & \multirow{2}{*}{$<0.001$} \\
\hline & No & $432(57.4 \%)$ & $6087(71.5 \%)$ & \\
\hline \multirow[t]{2}{*}{ Depression } & Yes & $223(29.7 \%)$ & $1572(18.5 \%)$ & \multirow{2}{*}{$<0.001$} \\
\hline & No & $529(70.3 \%)$ & $6939(81.5 \%)$ & \\
\hline \multirow[t]{2}{*}{ Insomnia } & Yes & $243(32.3 \%)$ & $1552(18.2 \%)$ & \multirow{2}{*}{$<0.001$} \\
\hline & No & $509(67.7 \%)$ & $6959(81.8 \%)$ & \\
\hline \multirow[t]{2}{*}{ Surgery history } & Yes & $408(54.3 \%)$ & $4052(47.7 \%)$ & \multirow{2}{*}{0.001} \\
\hline & No & $344(45.7 \%)$ & $4437(52.3 \%)$ & \\
\hline \multirow[t]{2}{*}{ Back pain or joint pain } & Yes & $591(78.6 \%)$ & $5702(67 \%)$ & \multirow{2}{*}{$<0.001$} \\
\hline & No & $161(21.4 \%)$ & $2809(33 \%)$ & \\
\hline \multirow[t]{2}{*}{ GERD } & Yes & $271(36 \%)$ & $2054(24.1 \%)$ & \multirow{2}{*}{$<0.001$} \\
\hline & No & $481(64 \%)$ & $6457(75.9 \%)$ & \\
\hline
\end{tabular}

$P$ was calculated by: $\mathrm{X} 2$ test or fisher exact test.

CC: Chronic constipation, HTN: hypertension, GERD: Gastroesophageal reflux disease

1.01-1.48), back pain or arthralgia (OR: $1.38,95 \% \mathrm{CI}$ : 1.14-1.67), insomnia (OR: 1.62, 95\% CI: 1.36-1.93), and GERD (OR: $1.51,95 \%$ CI: 1.28-1.78) were associated with higher prevalence of constipation in the multivariable analysis (table 4).

\section{DISCUSSION}

The prevalence of $\mathrm{CC}$ in our study was $8.1 \%(6.7 \%$ in men and $9.3 \%$ in women), which was less than the prevalence reported in most studies conducted in western countries. According to a systematic review in North America the prevalence ranged from $1.9 \%$ to $27 \%$ with an average of $15 \%$ in most studies. ${ }^{2}$ According to another meta-analysis the pooled prevalence in South America was $18 \%$, and in north and south Europe was $16 \%$, while in the middle eastern and southeast Asian studies were $14 \%$ and $11 \%$, respectively. ${ }^{7}$

According to SEPAHAN systematic review, the prevalence of CC ranged from $2.4 \%$ to $11.2 \%$ in Iran. ${ }^{19}$ In a study conducted in Tehran province, $2.4 \%$ of general population were diagnosed as having FC based on Rome
III criteria. ${ }^{20}$ Another study conducted in Isfahan showed that $9.6 \%$ of the participants had constipation according to self-reports. ${ }^{21}$ Another study conducted in Kerman, showed a prevalence of $9.4 \% .^{22}$

The prevalence estimated in our study, like other studies conducted in Iran, was lower than western countries. This can be due to different life style in Iranian population. $^{20,23}$ Iranian diet consists of more fibers (vegetable and fruits). Bread and rice is the main food in Iranian diet. ${ }^{24}$ Second reason of this lower prevalence may be the style of Iranian toilet. On a normal defecation, relaxation of the puborectalis and external anal sphincter with increased intra-abdominal pressure straighten the anorectal angle and lead in defecation. Due to full flexion of hip in Iranian toilet the anorectal angle is much wider than in European toilet. This wide angle helps complete evacuation. ${ }^{25}$ Our study also included individuals between aged between 40 and 75 years and all of them were from a rural district that both the age limitation and population selection can affect the prevalence.

In this study $\mathrm{CC}$ was more prevalent among female 
Table 4: Logistic regression analysis of factors associated with chronic constipation

\begin{tabular}{|c|c|c|c|c|c|c|}
\hline \multirow{2}{*}{ Variables } & & \multirow{2}{*}{$C C(n=752)$} & \multirow{2}{*}{ No CC $(n=8511)$} & \multirow{2}{*}{$P$ value } & \multicolumn{2}{|c|}{ Odds Ratio (95\% CI) } \\
\hline & & & & & Unadjusted & Adjusted \\
\hline \multirow[t]{2}{*}{ Opium used } & Yes & $100(13.3 \%)$ & $674(7.9 \%)$ & \multirow{2}{*}{$<0.001$} & $1.78(1.42-2.23)$ & $2.06(1.63-2.60)$ \\
\hline & No & $652(86.7 \%)$ & $7837(92.1 \%)$ & & reference & reference \\
\hline \multirow[t]{3}{*}{ Physical activity } & Low & $339(45.1 \%)$ & $2766(32.5 \%)$ & \multirow{3}{*}{$<0.001$} & reference & reference \\
\hline & Medium & $239(31.8 \%)$ & $2828(33.3 \%)$ & & $0.70(0.58-0.82)$ & $0.74(0.62-0.89)$ \\
\hline & High & $174(23.1 \%)$ & $2911(34.2 \%)$ & & $0.48(0.40-0.59)$ & $0.56(0.46-0.68)$ \\
\hline \multirow[t]{2}{*}{ Insomnia } & Yes & $243(32.3 \%)$ & $1552(18.2 \%)$ & \multirow{2}{*}{$<0.001$} & $2.14(1.82-2.52)$ & $1.62(1.36-1.93)$ \\
\hline & No & $509(67.7 \%)$ & $6959(81.8 \%)$ & & reference & reference \\
\hline \multirow[t]{2}{*}{ Anxiety } & Yes & $320(42.6 \%)$ & $2424(28.5 \%)$ & \multirow{2}{*}{$<0.001$} & $1.86(1.60-2.17)$ & $1.38(1.15-1.65)$ \\
\hline & No & $432(57.4 \%)$ & $6087(71.5 \%)$ & & reference & reference \\
\hline \multirow[t]{2}{*}{ Depression } & Yes & $223(29.7 \%)$ & $1572(18.5 \%)$ & \multirow{2}{*}{$<0.001$} & $1.86(1.58-2.2)$ & $1.22(1.01-1.48)$ \\
\hline & No & $529(70.3 \%)$ & $6939(81.5 \%)$ & & reference & reference \\
\hline \multirow{2}{*}{$\begin{array}{l}\text { Back pain or } \\
\text { joint pain }\end{array}$} & Yes & $591(78.6 \%)$ & $5702(67 \%)$ & \multirow{2}{*}{$<0.001$} & $1.80(1.51-2.17)$ & $1.38(1.14-1.67)$ \\
\hline & No & $161(21.4 \%)$ & $2809(33 \%)$ & & reference & reference \\
\hline \multirow[t]{2}{*}{ GERD } & Yes & $271(36 \%)$ & $2054(24.1 \%)$ & \multirow{2}{*}{$<0.001$} & $1.77(1.51-2.07)$ & $1.51(1.28-1.78)$ \\
\hline & No & $481(64 \%)$ & $6457(75.9 \%)$ & & reference & reference \\
\hline \multirow[t]{2}{*}{ Age } & $40-59$ years & $486(64.6 \%)$ & $6546(76.9 \%)$ & \multirow{2}{*}{$<0.001$} & reference & reference \\
\hline & $\geq 60$ years & $266(35.4 \%)$ & $1962(23.1 \%)$ & & $1.83(1.56-2.14)$ & $1.55(1.31-1.83)$ \\
\hline
\end{tabular}

CC: Chronic constipation, GERD: Gastroesophageal reflux disease

sex (female: male ratio $=1.44)$. Most of previous studies reported higher prevalence of CC among women. Based on a systematic review in North America, the female: male ratio was 2.2 in average. ${ }^{2}$ Another systematic review reported a female to male ratio of 2.1 , worldwide. ${ }^{26} \mathrm{In}$ previous studies conducted in Iran the female to male ratio ranged from 1.5 to $3.8 .{ }^{20-22,27,28}$ Female sex hormones can be contributed to this higher prevalence. Progesterone can prolong colonic transit time and this can lead to higher rate of constipation in luteal phase of menstrual cycle. ${ }^{29} \mathrm{~A}$ study showed that overexpression of progesterone receptors can lead to slow transit CC in women. ${ }^{30}$ Women are also more susceptible to pelvic floor injury due to obstetric trauma during childbirth, which may contribute to CC. According to a study, the prevalence of pelvic floor injury was significantly higher in individuals with constipation, however the cause or effect association was not established well yet. ${ }^{31}$

In our study the prevalence of $\mathrm{CC}$ increased with age. This association was confirmed in most previous studies. ${ }^{13,23,26,32}$ This may be due to higher rate of co-morbidities in elderly. Diabetes mellitus, hypothyroidism, chronic renal failure, cerebrovascular accident, etc. are some of these co-morbidities that can cause secondary CC. ${ }^{10}$ Another cause for higher prevalence of constipation in elderly may be lower energy intake and lower physical activity. ${ }^{20,33}$

There is also a positive association between physical activity and CC in our study. The rate of $\mathrm{CC}$ decreased to half in individuals with higher physical activity compared with physically inactive participants. Physical activity can increase propulsive movements in the large intestine. ${ }^{33,34}$ Hormonal change during exercise may also affect gastrointestinal (GI) motility. ${ }^{35}$

One of the most important factors that was associated with constipation in our study was opium consumption. The prevalence of constipation was higher among opium addicted men in our study and after adjusting for other variables, it was seen that opium consumption can cause a two fold increase in the prevalence of constipation. Although it is traditionally not consistent with the definition of functional GI disorder, a term known as "OpioidInduced Constipation" or OIC was added to the recent version of Rome criteria because it can present with similar symptoms as FC. ${ }^{8,36}$ Opioids have three different receptors in body ( $\delta, \kappa$, and $\mu$ receptors). $\mu$-receptors 
are widely distributed in the GI tract and their activation leads to decrease in GI propulsive and peristaltic motility, increase in non-propulsive GI motility, stimulation of ileocecal sphincter, and increase in anal sphincter tone. Activation of opioids receptors also decreases water and electrolyte secretions into GI lumen and increases fluid reabsorption from the gut. Slowing the intestinal transit is another factor that leads to more fluid reabsorption and makes the stool harder. All of these changes can cause or exacerbate constipation. ${ }^{37}$

Our study showed that the prevalence of insomnia was higher in individuals with constipation. A study on Chinese women aged over 50 years showed that poor sleep quality increased the chance of constipation up to three times. ${ }^{38}$

Positive associations of anxiety and depression with the prevalence of constipation were observed in our study. Previous studies showed an association between $\mathrm{CC}$ and some psychological disorders such as anxiety or depression. ${ }^{22,39-41}$ Antidepressant drugs such as Tricyclic Antidepressant (TCAs) can increase constipation. The underlying mechanism for psychological disorders have not been fully understood yet but it is believed that these disorders can influence gut-brain interaction and cause change in GI motility. ${ }^{42}$

In our study, frequent GERD was more prevalent in patients with constipation. In a study by Baran and colleagues, the overlap of GERD and functional constipation was investigated in children. It was seen that in children suffered from both GERD and FC, treatment of constipation led to a significant improvement in GERD symptoms. ${ }^{43}$ Another study in Korean patients reported that the overlap of GERD or functional dyspepsia was common in patients with constipation. ${ }^{44}$

The strength of our study is its large sample size and involvement of multiple variables that were available based on PCS questionnaire. We investigated the association between opium consumption and constipation in a large sample size. Limitations of our study are its cross-sectional design and age restriction from 40 to 75 years. Accordingly, the study may not be fully able to explain the cause-effect associations.

In conclusion, the overall prevalence of constipation is $8.1 \%$ in our population. The most important factors that were associated with constipation in our study were older age, physical inactivity, opium consumption, anxiety, depression, insomnia, back pain or arthralgia, and GERD. Decreasing modifiable risk factors associated with constipation such as opium consumption and physical inactivity can reduce its prevalence and decrease the burden of the disease.

\section{ETHICAL APPROVAL}

There is nothing to be declared.

\section{CONFLICT OF INTEREST}

The authors declare no conflict of interest related to this work.

\section{REFERENCES}

1. Choung RS, Branda ME, Chitkara D, Shah ND, Katusic SK, Locke III GR, et al. Longitudinal direct medical costs associated with constipation in women. Aliment Pharmacol Ther 2011;33:251-60. doi: 10.1111/j.13652036.2010.04513.x.

2. Higgins PD, Johanson JF. Epidemiology of constipation in North America: a systematic review. Am J Gastroenterol 2004;99:750-9. doi: 10.1111/j.1572-0241.2004.04114.x.

3. Longstreth GF, Thompson WG, Chey WD, Houghton LA, Mearin F, Spiller RC. Functional bowel disorders. Gastroenterology 2006;130:1480-91. doi: 10.1053/j.gastro.2005.11.061.

4. Jun DW, Park HY, Lee OY, Lee HL, Yoon BC, Choi HS, et al. A population-based study on bowel habits in a Korean community: prevalence of functional constipation and self-reported constipation. Dig Dis Sci 2006;51:1471-7.

5. Sorouri M, Pourhoseingholi MA, Vahedi M, Safaee A, Moghimi-Dehkordi B, Pourhoseingholi A, et al. Functional bowel disorders in Iranian population using Rome III criteria. Saudi J Gastroenterol 2010;16:154-60. doi: 10.4103/1319-3767.65183.

6. Basaranoglu M, Celebi S, Ataseven H, Rahman S, Deveci SE, Acik Y. Prevalence and consultation behavior of self-reported rectal bleeding by face-to-face interview in an Asian community. Digestion 2008;77:10-5. doi: $10.1159 / 000114827$

7. Suares NC, Ford AC. Prevalence of, and risk factors for, chronic idiopathic constipation in the community: systematic review and meta-analysis. Am J Gastroenterol 2011;106:1582-91. doi: 10.1038/ajg.2011.164.

8. Simren M, Palsson OS, Whitehead WE. Update on Rome IV Criteria for Colorectal Disorders: Implications for Clinical Practice. Curr Gastroenterol Rep 2017;19:15. doi: 10.1007/s11894-017-0554-0.

9. Basilisco G, Coletta M. Chronic constipation: a critical review. Dig Liver Dis 2013;45:886-93. doi: 10.1016/j. dld.2013.03.016. 
10. Mearin F, Ciriza C, Minguez M, Rey E, Mascort JJ, Pena E, et al. Clinical Practice Guideline: Irritable bowel syndrome with constipation and functional constipation in the adult. Rev Esp Enferm Dig 2016;108:332-63. doi: 10.17235/reed.2016.4389/2016.

11. Chu H, Zhong L, Li H, Zhang X, Zhang J, Hou X. Epidemiology characteristics of constipation for general population, pediatric population, and elderly population in China. Gastroenterol Res Pract 2014;2014:532734. doi: $10.1155 / 2014 / 532734$.

12. Choung RS, Locke GR 3rd, Rey E, Schleck CD, Baum $\mathrm{C}$, Zinsmeister AR, et al. Factors associated with persistent and nonpersistent chronic constipation, over 20 years. Clin Gastroenterol Hepatol 2012;10:494-500. doi: 10.1016/j.cgh.2011.12.041.

13. Pinto Sanchez MI, Bercik P. Epidemiology and burden of chronic constipation. Can J Gastroenterol 2011;25 Suppl B:11B-5B.

14. Sun SX, Dibonaventura M, Purayidathil FW, Wagner JS, Dabbous O, Mody R. Impact of chronic constipation on health-related quality of life, work productivity, and healthcare resource use: an analysis of the National Health and Wellness Survey. Dig Dis Sci 2011;56:268895. doi: 10.1007/s10620-011-1639-5.

15. Gandomkar A, Poustchi H, Moini M, Moghadami M, Imanieh H, Fattahi MR, et al. Pars cohort study of noncommunicable diseases in Iran: protocol and preliminary results. Int J Public Health 2017;62:397-406. doi: 10.1007/s00038-016-0848-2.

16. Palsson OS, Whitehead WE, van Tilburg MA, Chang L, Chey W, Crowell MD, et al. Rome IV Diagnostic Questionnaires and Tables for Investigators and Clinicians. Gastroenterology 2016. doi: 10.1053/j.gastro.2016.02.014.

17. Nejhad ZH, Vardanjani HM, Abolhasani F, Hadipour M, Sheikhzadeh K. Relative effect of socio-economic status on the health-related quality of life in type 2 diabetic patients in Iran. Diabetes Metab Syndr 2013;7:187-90. doi: 10.1016/j.dsx.2013.10.024.

18. Vardajani HM, Haghdoost AA, Shahravan A, Rad M. Cleansing and preparation of data for statistical analysis: A step necessary in oral health sciences research. $J$ Oral Health Oral Epidemiol 2016;5:171-85.

19. Iraji N, Keshteli AH, Sadeghpour S, Daneshpajouhnejad P, Fazel M, Adibi P. Constipation in Iran: SEPAHAN Systematic Review No. 5. Int J Prev Med 2012;3 Suppl 1:S34-41.

20. Kaboli SA, Pourhoseingholi MA, Moghimi-Dehkordi B, Safaee A, Habibi M, Pourhoseingholi A, et al. Factors associated with functional constipation in Iranian adults: a population-based study. Gastroenterol Hepatol Bed Bench 2010;3.

21. Adibi P, Behzad E, Pirzadeh S, Mohseni M. Bowel habit reference values and abnormalities in young Iranian healthy adults. Dig Dis Sci 2007;52:1810-3. doi: 10.1007/ s10620-006-9509-2.
22. Zahedi MJ, Moghadam SD, Abbasi MHB, Mirzaei SMS, Shafieipour S. The assessment prevalence of functional constipation and associated factors in adults: a community-based study from Kerman, Southeast, Iran (20112012). Govaresh 2014;19:95-101.

23. Patimah AW, Lee YY, Dariah MY. Frequency patterns of core constipation symptoms among the Asian adults: a systematic review. BMC Gastroenterol 2017;17:115. doi: 10.1186/s12876-017-0672-z.

24. Davudi K, Volkova L. Structure of nutrition in Iranian population. Vopr pitan 2007;76:56-61.

25. Rad S. Impact of ethnic habits on defecographic measurements. Arch Iran Med 2002;5:115.

26. Mugie SM, Benninga MA, Di Lorenzo C. Epidemiology of constipation in children and adults: a systematic review. Best Pract Res Clin Gastroenterol 2011;25:3-18. doi: 10.1016/j.bpg.2010.12.010.

27. Pourhoseingholi A, Safaee A, Pourhoseingholi MA, Boghimi-Dehkordi B, Habibi M, Vahedi M, et al. Prevalence and demographic risk factors of gastrointestinal symptoms in Tehran province. Italian J Public Health 2012;7.

28. Khoshbaten M, Hekmatdoost A, Ghasemi H, Entezariasl M. Prevalence of gastrointestinal symptoms and signs in northwestern Tabriz, Iran. Indian $J$ Gastroenterol 2004;23:168-70

29. Jung HK, Kim DY, Moon IH. Effects of gender and menstrual cycle on colonic transit time in healthy subjects. Korean J Intern Med 2003;18:181-6. doi: 10.3904/ kjim.2003.18.3.181.

30. Xiao Z-L, Pricolo V, Biancani P, Behar J. Role of progesterone signaling in the regulation of G-protein levels in female chronic constipation. Gastroenterology 2005;128:667-75. doi: 10.1053/j.gastro.2004.12.001.

31. Amselem C, Puigdollers A, Azpiroz F, Sala C, Videla S, Fernandez-Fraga X, et al. Constipation: a potential cause of pelvic floor damage? Neurogastroenterol Motil 2010;22:150-e48. doi: 10.1111/j.13652982.2009.01409.x.

32. Peppas G, Alexiou VG, Mourtzoukou E, Falagas ME. Epidemiology of constipation in Europe and Oceania: a systematic review. BMC Gastroenterol 2008;8:5. doi: 10.1186/1471-230X-8-5.

33. Holdstock D, Misiewicz J, Smith T, Rowlands E. Propulsion (mass movements) in the human colon and its relationship to meals and somatic activity. Gut 1970;11:91-9. doi: 10.1136/gut.11.2.91

34. De Schryver AM, Keulemans YC, Peters HP, Akkermans LM, Smout AJ, De Vries WR, et al. Effects of regular physical activity on defecation pattern in middle-aged patients complaining of chronic constipation. Scand J Gastroenterol 2005;40:422-9. doi: 10.1080/00365520510011641.

35. Dukas L, Willett WC, Giovannucci EL. Association between physical activity, fiber intake, and other lifestyle variables and constipation in a study of women. Am J Gastroenterol 
2003;98:1790-6. doi: 10.1111/j.1572-0241.2003.07591.x.

36. Mearin F, Lacy BE, Chang L, Chey WD, Lembo AJ, Simren M, et al. Bowel Disorders. Gastroenterology 2016. doi: 10.1053/j.gastro.2016.02.031.

37. Leppert W. The impact of opioid analgesics on the gastrointestinal tract function and the current management possibilities. Contemp Oncol (Pozn) 2012;16:125-31. doi: 10.5114/wo.2012.28792.

38. Huang L, Jiang H, Zhu M, Wang B, Tong M, Li H, et al. Prevalence and Risk Factors of Chronic Constipation Among Women Aged 50 Years and Older in Shanghai, China. Med Sci Monit 2017;23:2660-7. doi: 10.12659/ MSM.904040.

39. Cheng C, Chan AO, Hui WM, Lam SK. Coping strategies, illness perception, anxiety and depression of patients with idiopathic constipation: a population-based study. Aliment Pharmacol Ther 2003;18:319-26. doi: 10.1046/j.1365-2036.2003.01663.x.

40. Mason HJ, Serrano-Ikkos E, Kamm MA. Psychological morbidity in women with idiopathic constipation. American J Gastroenterol 2000;95:2852-7. doi: 10.1111/j.15720241.2000.02313.x.

41. Mody R, Guerin A, Fok B, Lasch KL, Zhou Z, Wu EQ, et al. Prevalence and risk of developing comorbid conditions in patients with chronic constipation. Curr Med Res Opin 2014;30:2505-13. doi:10.1185/03007995.2014.964854.

42. Wouters M, Boeckxstaens G. Is there a causal link between psychological disorders and functional gastrointestinal disorders? Expert Rev Gastroenterol Hepatol 2016;10:5-8. doi: 10.1586/17474124.2016.1109446.

43. Baran M, Appak YC, Karakoyun M, Yalcinkaya S, Eliacik $\mathrm{K}$, Dundar BN. The overlap of gastroesophageal reflux disease and functional constipation in children: the efficacy of constipation treatment. Eur J Gastroenterol Hepatol 2017;29:1264-8. doi:10.1097/MEG.0000000000000979.

44. Park KS, Jee SR, Lee BE, Hong KS, Shin JE, Na SY, et al. Nationwide multicenter study for overlaps of common functional gastrointestinal disorders in Korean patients with constipation. J Neurogastroenterol Motil 2017;23:569-77. doi:10.5056/jnm17033. 